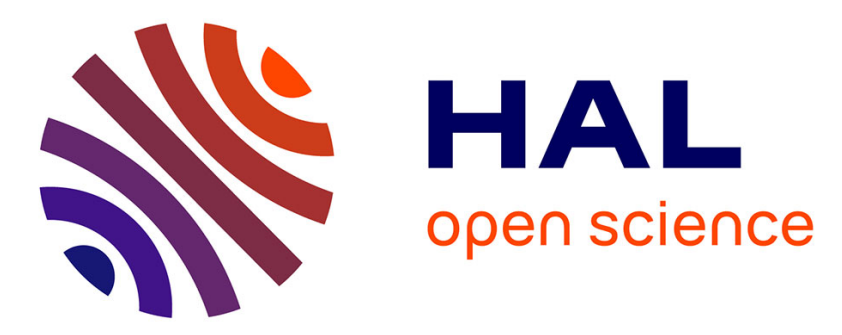

\title{
Terahertz nondestructive stratigraphic analysis of thick plastic sheets with complex structure
}

\author{
Min Zhai, A. Locquet, D.S. Citrin
}

\section{To cite this version:}

Min Zhai, A. Locquet, D.S. Citrin. Terahertz nondestructive stratigraphic analysis of thick plastic sheets with complex structure. 2021 46th International Conference on Infrared, Millimeter and Terahertz Waves (IRMMW-THz), Aug 2021, Chengdu, China. 10.1109/IRMMWTHz50926.2021.9567144 . hal-03419881

\section{HAL Id: hal-03419881 \\ https://hal.science/hal-03419881}

Submitted on 8 Nov 2021

HAL is a multi-disciplinary open access archive for the deposit and dissemination of scientific research documents, whether they are published or not. The documents may come from teaching and research institutions in France or abroad, or from public or private research centers.
L'archive ouverte pluridisciplinaire HAL, est destinée au dépôt et à la diffusion de documents scientifiques de niveau recherche, publiés ou non, émanant des établissements d'enseignement et de recherche français ou étrangers, des laboratoires publics ou privés. 


\title{
Terahertz nondestructive stratigraphic analysis of thick plastic sheets with complex structure
}

\author{
Min Zhai, Alexandre Locquet, and D.S. Citrin \\ Georgia Tech-CNRS IRL2958, Georgia Tech Lorraine, 2 Rue Marconi, 57070 Metz, France \\ School of Electrical and Computer Engineering, Georgia Institute of Technology, Atlanta, GA 30332-0250 USA
}

\begin{abstract}
SD based on interior point method is used to extract structural information of a sample incorporating both optically thick and thin layers. Pulse spreading is taken into consideration as the THz signal propagates through the thick layers. Compared with both cross-correlation (CC) and frequency wavelet-domain deconvolution (FWDD), the proposed SD algorithm succeeds in resolving the structure of the sample clearly, demonstrating that SD-based approaches might be the preferred option in the presence of both the thick and thin layers.
\end{abstract}

\section{INTRODUCTION}

$\mathrm{T}$ o date, THz-based techniques have attracted considerable interest for characterizing various nonmetallic materials. We considered here specimens containing both thick and thin layers. Dispersion is observed and cannot be neglected when analyzing the reflected signal. Even though the cross-correlation (CC) approach, in conjunction with quasi-Dirac-function dispersion model [1] succeeds in characterizing thick plastic materials with simple structure, several drawbacks, such as the failure to separate overlapped echoes, limit its applicability when addressing signals in the absence of structural information. Based on the nature of SD, interior-point method together with dispersive propagation model, is utilized in this work, and its performance is compared to both FWDD- and CC- based algorithms.

\section{RESULtS}
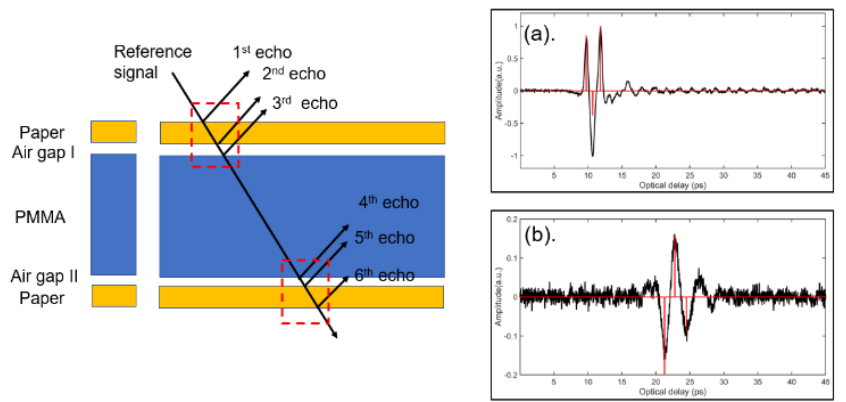

Fig. 1. The comparison between the deconvolved results by SD (red) and the raw reflected signal (black) from the front of sample (a), and the back of sample (b).

One sample with five-layer structures is investigated in this work and a schematic diagram of the sample is shown in Fig. 1. A layer of standard copy paper is placed on each side of a thick PMMA plastic sheet $(6 \mathrm{~mm})$, and airgaps are introduced intentionally between the paper layer and PMMA. The thickness of paper is measured first using high-resolution caliper, which is $\sim 90 \mu \mathrm{m}$.

Owing to the negative frequency-dependent refractive index $n(v)$ observed in transmission results, in order to achieve a better structural representation of the back of the sample, the signal transmitted through the back PMMA/airgap interface serves as the incident signal and can be simulated based on the dispersion model in Ref. [3]. Different from the quasi-Dirac $\delta$-function dispersion we used in Ref. [1], no tunable parameters are required when taking dispersion into account.

Figures 1(a) and (b) show the raw reflected signals from the front and back of the sample, and the corresponding deconvolved results by SD after accounting for dispersion. "Quasi-ideal" deconvolved results are presented, and all interfaces are successfully observed. The
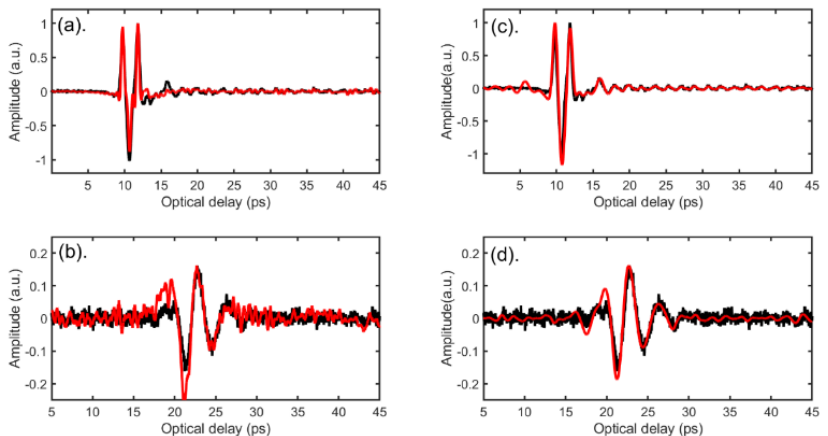

Fig. 2. The comparison between the deconvolved result for signal reflected from the front of sample by FWDD (a) and CC (c); The comparison between the deconvolved result for signal reflected from the back of sample by FWDD (b) and CC (d).

thicknesses of paper, air gap, and PMMA sheet, calculated based on SD results, are $\sim 87 \mu \mathrm{m}, \sim 167 \mu \mathrm{m}$, and $\sim 5.921 \mathrm{~mm}$, respectively, showing excellent agreement with the reference values measured directly with a high-resolution caliper.

The performances of FWDD and CC are also tested, and the corresponding deconvolved results are presented in Fig. 2. Owing to the low SNR of the signal reflected from back of specimens, some valuable information might be treated as noise and filtered out by the high-frequency filters. Moreover, it is difficult to select an optimal wavelet base function that is suitable for the front- and back-surface reflections owing to the constant change of the waveform of reflected signals. For CC, even though it is a powerful tool of extracting signals from noisy environments, it is incapable of separating two overlapping echoes. In addition, the deconvolved results by FWDD and CC cannot be directly utilized for subsequent peak-detection because of the residual noise.

Regarding thickness estimation, after numerous simulations, we find that the maximum thickness that can be resolved by SD is lower than CC. Although SD fails to provide the thickness of the thickest samples, it is still the preferred option in some cases such as specimens with both thick and thin layers.

\section{SUMMARY}

SD based on an interior-point method is utilized to characterize a thick sample with complex structure. A dispersion model is also incorporated to compensate for pulse spreading. Better performance is found compared with the FWDD and CC techniques, demonstrating that the SD-based approach may be more suitable for structural characterization of specimens that contain both thick and thin layers simultaneously.

\section{REFERENCES}

[1]. M. Zhai, A. Locquet, and D.S. Citrin, "Pulsed THz imaging for thickness characterization of plastic sheets," NDT\&E Int., 116:102338, 2020.

[2]. K. Koh, S.J. Kim, and S. Boyd, "An interior-point method for large-scale 1-regularized logistic regression," J. Mach. Learn, Res., 1519-55, 2007.

[3]. Y. Chang, Y. Zi, J. Zhao, Z. Yang, W. He, and H. Sun, "An adaptive sparse deconvolution method for distinguishing the overlapping echoes of ultrasonic guided waves for pipeline crack inspection," Meas. Sci. Technol., 28(3):035002, 2017. 